\title{
The Dynamics of Land Use Land Cover and its Driving Forces in Mekelle City
} Region, Ethiopia

\section{Shishay Kiros Weldegebriel ${ }^{1}$ Kumelachew Yeshitela ${ }^{2}$}

'Ethiopian Civil Service University, Addis Ababa, Ethiopia.

Email:shishaykiros@gmail.com

${ }^{2}$ Ethiopian Institute of Architecture, Building Construction and City Development, Addis Ababa University, Addis Ababa, Ethiopia.

\footnotetext{
年
}

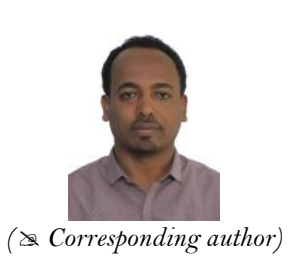

Abstract

The rationale of this study was to study the spatio-tempo LULC dynamics over the past 47 years and identifying the major drivers of these changes. It was conducted in Mekelle city region, northern Ethiopia which is highly susceptible to environmental degradation. This landscape-scale level study employs a combination of analysis of satellite imageries, information from field studies, document review, key informant interview and observation. Digital satellite images were processed, classified and analysed by ERDAS Imagine. Computations of the area changes in the land use categories was made using supervised classification by applying maximum likelihood classifier algorithm and finally post-classification change detection technique was undertaken using Arc GIS 10.5.1. For stastical analysis of variables spatial autocorrelation and structural equation model was used. During the study period between 1972 and 2019 about 60,705.56 hectares of the total landscape of the study area was converted from one LULC type to another. The findings show increase was observed in cultivated land, built-up area and bushes and shrubs. On the other hand, natural forest, water body and bare lands were dramatically declined. Among the driving factors; climate variability, population growth, DEM and slope were identified as the leading land use and land cover change drivers. Thus, spatial planners need to take these drivers into consideration and make sound decisions regarding changes in LULC during decision makings.

Keywords: City region, Drivers, ERDAS, Land use/land cover changes, Remote sensing, Spatio-tempo.

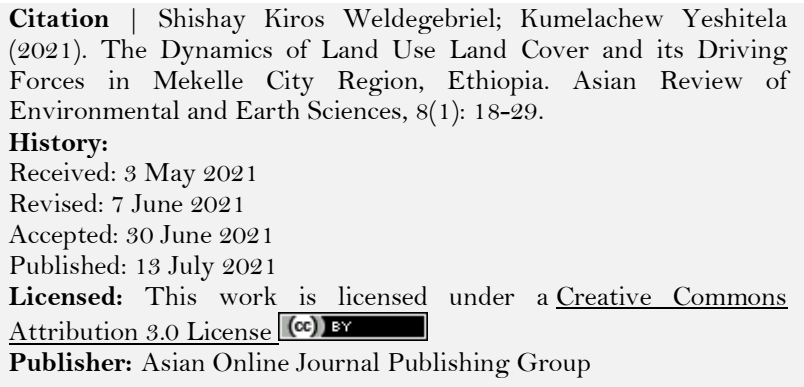

Citation | Shishay Kiros Weldegebriel; Kumelachew Yeshitela (2021). The Dynamics of Land Use Land Cover and its Driving Forces in Mekelle City Region, Ethiopia. Asian Review of Environmental and Earth Sciences, 8(1): 18-29. History:

Received: 3 May 2021

Revised: 7 June 2021

Accepted: 30 June 2021

Published: 13 July 2021

Licensed: This work is licensed under a Creative Commons Attribution 3.0 License (c)

Publisher: Asian Online Journal Publishing Group

Acknowledgement: My thanks go to Tigray Bureau of trade, industry and urban development, Tigray (Ethiopia), bureau of civil service and Ethiopian civil service university for giving the opportunity to pursue this study, without which this achievement would not have been possible. Authors would like to thank all institutions and individuals at national, regional, district and city levels who provided them information for this study.

Funding: This study received no specific financial support

Competing Interests: The authors declare that they have no conflict of interests.

Transparency: The authors confirm that the manuscript is an honest, accurate, and transparent account of the study was reported; that no vital features of the study have been omitted; and that any discrepancies from the study as planned have been explained.

Ethical: This study follows all ethical practices during writing.

\section{Contents}

1. Introduction

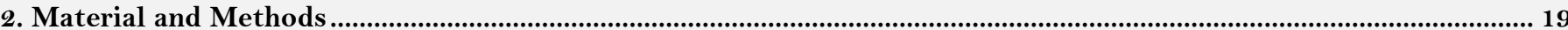

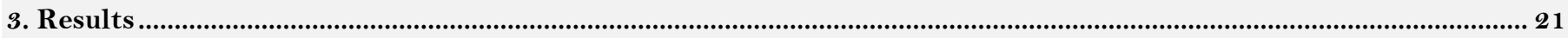

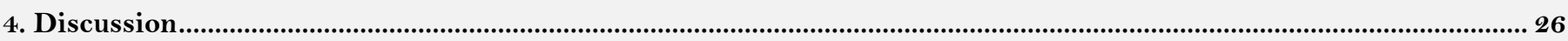

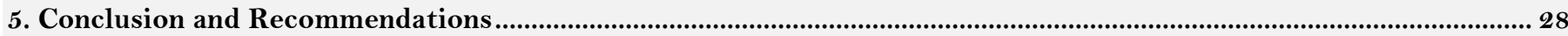

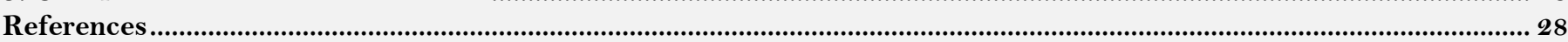




\section{Contribution of this paper to the literature}

This study contributes to the generation of scientific knowledge for the scientific community on understanding environmental degradation using multi-lens approach to sustain the environment, improved research tool/ technique and it will have implications for positive social change.

\section{Introduction}

The imminent of humankind depends on whether or not we have a vision to guide transition toward sustainability, on scales ranging from local landscapes to the planet as a whole [1]. The fundamental concept in landscape development has always been that people are part of the landscape and that landscapes are changed for their benefit [2]. In order to meet increasing human needs natural ecosystems have been converted into different land uses since humans first began to manage their environment. However, the changes that have taken place over the last 50 years have been especially important and intense as society is becoming increasingly urbanized, while natural ecosystems become deteriorated [3]. Land uses/land covers are closely related to the ecosystem services supply of provisioning, regulating, supporting and cultural ecosystem services provisions [4]. The dynamics of an ecosystem are strongly affected by natural and human disturbances, and such changes can have direct and cascading effects on the spatial and temporal variations of ecosystems [2]. The notion of driving forces is gaining increasing attention in landscape change research [5]. Drivers of degradation can be many and complex, resulting from a range of different interactions over time and space [6]. Anthropogenic drivers, such as population growth have mostly a short-term and often more perceivable impact than biophysical drivers. Conversely, climate change as one of the emerging drivers of land use / land cover dynamics and is difficult to detect and quantify in the short term. Subsequently, long-term studies are necessary to provide evidence of climate change [7]. Cities do not operate in isolation but within a sphere of dependence on surrounding areas and their ecosystems. Cities depend on persisting flows of goods and services coming from other neighbouring non-urban ecosystems to sustain fundamental urban functions.Ecological principles of land use advocate to examine the impacts of local decisions in a regional context [8]. Mekelle city is dependent on the ecosystem services beyond the city limits. Mekelle city has not been studied as a complete network with consideration of all ecosystem sources from its hinterlands. An increasing number of studies demonstrate the need of applying a social-ecological system approach in ecosystem services. However, there is a lack of empirical research that operationalizes the concept of social-ecological system in a spatially explicit. Several efforts have been made to improve the quantification of LULC changes and their drivers. From the reviewed literatures there are still deficiencies and methodological inconsistencies. Alternative approaches to better understand the problem is useful. Hence, studying landscape dynamics and its driving forces in Mekelle city region, northern Ethiopia through a social-ecological systems perspective under different spatial and temporal scales can support decision-making in land use to understand past, current and plausible future changes in land use. Therefore, the objectives of this study were: to assess land use/land cover dynamics, analyze the driving forces of land use/land cover change and suggest possible spatial planning solutions for sustainable watershed ecosystem services provision.

\section{Material and Methods}

\subsection{Study Area}

Mekelle city and its hinterlands which are significant in terms of watershed ecosystem services for the metropolitan city are named as city region (Figure 1). The landscape is located within Tigray region, northern part of Ethiopia found in west 39.362942, East 39.687048, North 13.680920 and south 13.342621 about $760.61 \mathrm{~km}$ north of Addis Ababa and the area covered in this investigation is 897.12 square kilometers (89,712 hectares).

The study area is characterized by varied topographic conditions. The elevation ranges from 1700 meters in the Geba river to 2685 meters Ellala and Gebat river catchment. The core city of the study area Mekelle city is $2062 \mathrm{~m}$ above sea level. The climate is predominantly semi-arid with irregular rainfall and frequent drought periods. The mean annual rainfall of the is estimated to be less than $532 \mathrm{~mm}$ [9]. Climatically, the area has a semiarid climate with little variation and it is knowns by its environmental vulnerability [10]. The agro-climatic zone of the study area is mild climatic condition. The monthly mean minimum temperature is $15^{\circ} \mathrm{C}$ and maximum monthly temperature may go as high as $28^{\circ} \mathrm{C}$. The study area population is 556127 [11].

\subsection{Data Sources and Processes}

This landscape-scale level study employs a combination of analysis of satellite imageries of 47 years and information from field studies, document review and key informant interview. In order to detect LULC dynamics data from Landsat series was extracted (Table 1) which is found at (https://earthexplorer.usgs.gov/.Key informant selection was made based on the information gathered from knowledgeable local elders; based on their age, duties and responsibility in their local community. Remotely sensed data, document review analyses add to validate the relevance of the local elderly interview results. In addition to this, the author made observations and described about what was observed. A global positioning system was used during the field survey for accuracy assessment.

The years for analysis were selected based on key signs of LULC change, e.g. land degradation, land policy changes, rapid urbanization, rapid population growth, Socio-economic development and finally the availability of satellite image. Images from the same period (November-January), i.e., immediately after the rainy season, was selected in order to minimize the seasonal effect on the classification results. Probability and non-probability sampling techniques was employed. Snowball sampling was employed for reaching local elderly persons. The population of LULC was divided into sub-populations of known size, and then random samples was taken from each stratum. In each category, random samples were further determined for field investigation. Since it is difficult to cover, collect data from whole population of ecosystem from all types of LULC for ground truthing using GPS it was selected proportional from all the city region by employing an accuracy assessment framework. The maps were further verified from the pre-determined sites through observations and consulting with 15 local residents. The 450 corroboration points, which were spatially and temporally distributed in the whole study area encompassing all nine LULC types Table 2 were sampled through stratified random sample. 


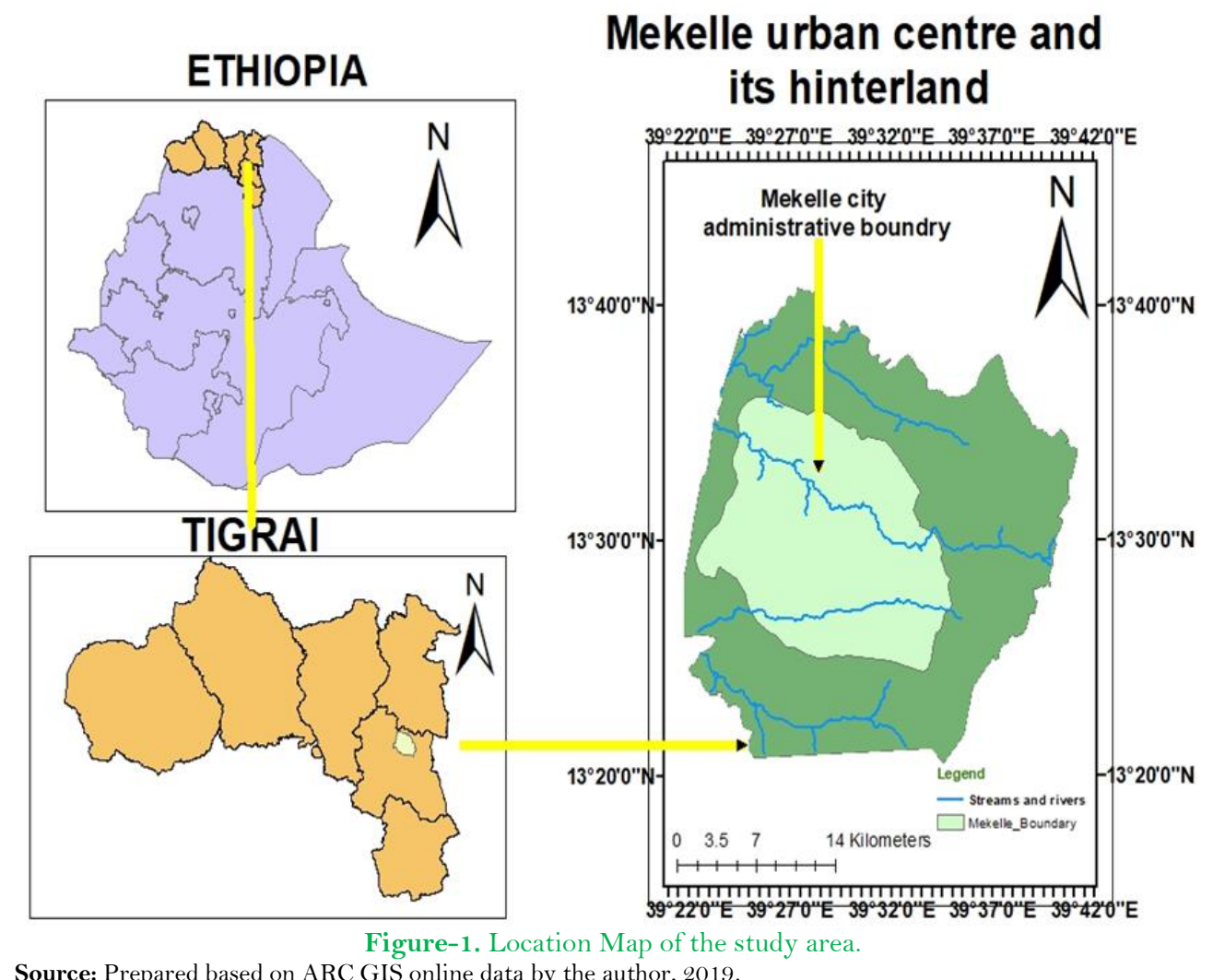

Source: Prepared based on ARC GIS online data by the author, 2019

Table-1. Specifications of satellite images that was utilized in this study.

\begin{tabular}{l|l|c|c|c|c}
\hline Satellite & Sensor & Path & Row & Resolution (m) & Acquisition date \\
\hline Landsat 1 & MSS Multispectral C1 level 1 & 181 & 50 & 60 & O2 November,1972 \\
\hline Landsat 5 & TM Multispectral C1 level 1 & 169 & 51 & 30 & 22 november,1984 \\
\hline Landsat 5 & TM Multispectral C1 level 1 & 168 & 51 & 30 & 21 november,1992 \\
\hline Landsat 5 & TM Multispectral C1 level 1 & 168 & 51 & 30 & 30 November,2001 \\
\hline Landsat 7 & ETM+ Multispectral C1 level 1 & 168 & 51 & 30 & 20 November,2012 \\
\hline Landsat 8 & Operational Land Imager OLI/TIRS C1 level 1 & 169 & 51 & 30 & 23 January,2019 \\
\hline
\end{tabular}

Table-2. Descriptions of identified LULC classes.

\begin{tabular}{l|l}
\hline LULC class & Description \\
\hline Built-up area & $\begin{array}{l}\text { Built-up area encompasses land on which buildings and non-building structures are present, such as urban } \\
\text { area of Mekelle city and its suburban area ,developed land lot including roads,rural area, small towns } \\
\text { and villages }\end{array}$ \\
\hline Grassland & $\begin{array}{l}\text { Land under grass cover but highly managed for grazing and feeding of domestic animals, selling for various } \\
\text { purposes. A land dominated by natural grass, small herbs and grazing lands. }\end{array}$ \\
\hline Cultivated land & $\begin{array}{l}\text { Areas of land prepared for growing agricultural crops. This category includes areas currently under crop, } \\
\text { Irrigated agricultural and land under preparation or fallow land. }\end{array}$ \\
\hline $\begin{array}{l}\text { Bushes and } \\
\text { Shrubs }\end{array}$ & $\begin{array}{l}\text { Land covered with shrubs, bushes, and small trees with little woody vegetation mixed. Specific area } \\
\text { characterized by scattered bushes and shrubs and trees. Areas covered by low woody of } 3 \text { m in height, } \\
\text { multiple stems, vertical growing of bushes and shrubs with canopy cover between 5 and 50\%. Examples like } \\
\text { Acacia locally known as "Hohot", Aloe barbadensis, "ika" and Ocimun lamiifolium. }\end{array}$ \\
\hline Water body & $\begin{array}{l}\text { surface water or all areas of open water areas covered with water either along the river bed or man-made } \\
\text { including rivers, streams, swales, dams, lakes, wetlands, ponds and reservoirs }\end{array}$ \\
\hline Natural Forest & High and dense natural forest and in churches and reserved Areas. \\
\hline Bare lands & $\begin{array}{l}\text { land left without vegetation cover (devoid vegetation), eroded land due to land degradation and weathered } \\
\text { road surface and includes rock, including exposed soils, stock quarry, rocks, and areas of active excavation } \\
\text { and vacant land within Mekelle city }\end{array}$ \\
\hline $\begin{array}{l}\text { Plantation } \\
\text { forest }\end{array}$ & $\begin{array}{l}\text { Areas covered by man-made trees including sparse forests examples include; Eucalyptus tree, acacia and } \\
\text { teak }\end{array}$ \\
\hline Riverside vegetation & $\begin{array}{l}\text { Plants growing in areas adjacent to rivers and streams in both urban and rural (Riparian vegetation include } \\
\text { trees, shrubs, grasses and trees with canopy.) }\end{array}$ \\
\hline
\end{tabular}

\subsection{Data Analysis}

Digital satellite images were processed, classified and analysed using ERDAS Imagine remote sensing software package 2015. Computations of the area and changes in the land use categories was made using Arc GIS 10.5.1. Supervised classification was performed on the image's pixels of the different LULC classes. This was done by training the areas (assigning pixels to land use classes) based on the previous knowledge of the area. Before classifying, the image was pre-processed in ERDAS software. The image was atmospheric corrected.

Landsat 7 ETM+ since 2003 to present has gaps in their data due to Scan Line Corrector (SLC) failure. Before analysis started scanning line corrector (SLC) was employed using SLC corrected in Arc GIS. The LULC of several years was converted to feature class(polygon) using Arc GIS conversion tool and using analysis tool of over lay tool using intersecting tool were merged into one polygon and then the 6 polygons were merged into single polygon. Then it was used calculate geometry to calculate the changes in hectares.

The LULC change detection LULC map of 1972 was re-sampled from 60m to 30 meters to match the spatial resolution of all the classified maps. Spatial autocorrelation (Moran's I) was used to derive detailed information of the spatial and temporal variation of the land-use land cover dynamics using a spatial statistics tool analyzing patterns in Arc GIS. To understand the possible drivers of changes structural equation model using STATA was used Table 6. 


\section{Results}

\subsection{Accuracy Assessment}

To assess the accuracy, first visual inspection for the image acquired from Landsat series was compared with LULC map prepared and with shape file the study area, local maps and google earth were used as first necessary step. Since this is not sufficient, quantitative accuracy assessmentt have made. To examines the accuracy assessment of land use land cover classified was done using ERDAS imagine 2015 accuracy assessment tool, for the year 2019 based on user defined 450 points collected referenced data using hand held GPS Table 3.

Total accuracy $=\quad$ Number of correct plots $* 100$

Total number of reference data

Accuracy total $=409 / 450 * 100=\underline{90.88 \%}$

The error percentage, is the number of sites incorrectly classified divided by 450 or $41 / 450=$ error, $=9.12 \%$. The overall accuracy and Kappa coefficient of the 2019 map were $90.88 \%$ and $91.64 \%$, respectively which is acceptable in both accuracy total and Kappa accuracy.

\begin{tabular}{l|l|c|c|c|c|c}
\hline Table-3. Comparing user's and producer's accuracies. \\
\hline S. N & Class name & $\begin{array}{c}\text { Reference } \\
\text { total }\end{array}$ & $\begin{array}{c}\text { Classified } \\
\text { total }\end{array}$ & $\begin{array}{c}\text { Number } \\
\text { correct }\end{array}$ & $\begin{array}{c}\text { Producer } \\
\text { accuracy }\end{array}$ & $\begin{array}{c}\text { User } \\
\text { accuracy }\end{array}$ \\
\hline 1 & Built-up area & 50 & 49 & 48 & 96 & 97.95 \\
\hline 2 & Natural forest & 50 & 44 & 44 & 88 & 10 \\
\hline 3 & Plantation forest & 50 & 55 & 47 & 94 & 85.45 \\
\hline 4 & Water bodies & 50 & 49 & 49 & 98 & 100 \\
\hline 5 & Cultivated land & 50 & 56 & 46 & 92 & 82.14 \\
\hline 6 & Grass land & 50 & 53 & 45 & 90 & 84.90 \\
\hline 7 & Bushes and shrubs & 50 & 49 & 48 & 96 & 97.95 \\
\hline 8 & River side vegetation & 50 & 47 & 39 & 78 & 82.97 \\
\hline 9 & Bare land & 50 & 45 & 43 & 86 & 95.55 \\
\hline & Total & 450 & 447 & 409 & 90.88 & 91.87 \\
\hline
\end{tabular}

The user and producer accuracy for any given class typically were not the same. In the above examples the producer's accuracy (It is the number of reference sites classified accurately divided by the total number of reference sites for the class) for the built-up class is $96 \%$ while the user's accuracy (It was calculated by taking the total number of correct classifications for a particular class and dividing it by the row total or the total number of classified sites) was $97.95 \%$. This means that even though $96 \%$ of the reference built-up areas have been correctly identified as built-up area, only $97.95 \%$ percent of the areas identified as built-up areas in the classification were actually built-up areas. Cultivated land (2) areas were mistakenly classified as built-up areas. By analyzing the various accuracy and error metrics we can better evaluate the analysis and classification results.

\subsubsection{Land Use/Land Cover Change Dynamics and Change Detection in Mekelle City Region}

The multi-temporal LULC results and the variations for the years 1972, 1984, 1992,2001,2012 and 2019 (Figure 2 and Table 5) illustrate in 1972 the area was occupied by different classes of built-up area, natural and plantation forest, water body, cultivated land, grass land, bushes and shrubs, river side vegetation and bare lands. The study area witnessed large amount of agriculture land converted into settlements and other urban development activities. Water bodies decreased. Dense forest comprising all land with tree cover of canopy density was significantly declined. The results from the classified image of 1972 illustrate that at the beginning of the study year $66.78 \%$ of the area was occupied by three land use classes only namely cultivated land, bare land and water body consecutively. And 26,403 ha (29.43\%), 19936 ha (19.99\%),15,577 ha (17.36\%),11,132(12.42\%),8183 ha $(9.12 \%), 5543(6.18 \%), 2359$ ha $(2.63 \%), 2082 \mathrm{ha}(2.32 \%)$ and 497 ha $(0.55 \%)$ was cultivated land, bare land, water body, river side vegetation, bushes and shrubs, natural forest, plantation forest, grass land and built-up area consecutively. The end of the study period 2019 reveals that cultivated land, bushes and shrubs and built-up land have tremendously expanded at the expenses of other ecosystem types. Currently,64,843 ha (72.27\%),13,215 ha $(14.73 \%), 8897$ ha $(9.92 \%), 1235(1.38) 497$ ha (0.55 \%),330 ha (0.37\%),326 ha (0.36\%),263 ha (0.29), and 106 ha $(0.13 \%)$ are cultivated land, bushes and shrubs, built-up area, river side vegetation, plantation forest, grass land, bare land, water body, and natural forest consecutively.

\subsubsection{Land-Use and Land-Cover Change Matrix}

The LULC changes matrix from 1972-2019 (Table 4) showed that; in sum, 749 hectares converted from builtup to other classes. However, there was no transformation from built-up to natural forest. Another 5427.73 hectares were converted from natural forest to other classes. This result showed majority of the natural forest was converted to cultivated land. Of the changed area, 1585 hectares converted from plantation forest to other classes. This result showed majority of the natural forest was converted to cultivated land. There was no transformation from water body to bushes and shrubs. In sum, 15314 hectares converted from water bodies to other classes. This result showed majority of the water bodies was converted to cultivated land followed by grass land and built-up areas. Similarly, 5160 hectares were converted from cultivated land to other classes. This result showed majority of cultivated land was converted to built-up areas. Compared to the other LULC, 2029.03 hectares were also converted from grass land to other classes. This showed majority of the grass land was transformed to cultivated land. Similarly, 2933.8 hectares converted from bushes and shrubs into other classes and majority of the bushes and shrubs was converted to cultivated land. On the other hand, 9897 hectares converted from river side vegetation into other classes. This result showed majority of the bushes and shrubs were converted to cultivated land. Finally, 17610 hectares converted from bare lands into other classes. This result revealed majority of the class was converted to cultivated land. 
Table-4. Summary of LULC change matrix in hectare from 1972 to 2019

\begin{tabular}{|c|c|c|c|c|c|c|c|c|c|c|c|c|c|c|c|}
\hline \multirow{2}{*}{\multicolumn{2}{|c|}{ To }} & \multicolumn{14}{|c|}{ From } \\
\hline & & \multicolumn{2}{|c|}{ Built-up area } & \multicolumn{2}{|c|}{ Natural Forest } & \multicolumn{2}{|c|}{$\begin{array}{c}\text { Plantation } \\
\text { forest }\end{array}$} & $\begin{array}{l}\text { Water } \\
\text { body }\end{array}$ & $\begin{array}{c}\text { Cultivated } \\
\text { land }\end{array}$ & Grass land & $\begin{array}{c}\text { Bushes } \\
\text { and shrubs }\end{array}$ & \multicolumn{2}{|c|}{$\begin{array}{l}\text { Riverside } \\
\text { vegetation }\end{array}$} & $\begin{array}{l}\text { Bare } \\
\text { land }\end{array}$ & $\begin{array}{l}\text { Total } \\
(2019)\end{array}$ \\
\hline \multicolumn{2}{|c|}{ Built-up area } & \multicolumn{2}{|c|}{42.9} & \multicolumn{2}{|l|}{0.74} & \multicolumn{2}{|c|}{0.40} & 1726.6 & 3516.72 & 0 & 1.44 & \multicolumn{2}{|c|}{522.31} & 3676.2 & 9487.31 \\
\hline \multirow{2}{*}{\multicolumn{2}{|c|}{$\frac{\text { Natural forest }}{\text { Plantation forest }}$}} & & 0 & \multirow{2}{*}{\multicolumn{2}{|c|}{$\frac{12.2}{349}$}} & \multicolumn{2}{|c|}{1.30} & 0.24 & 1.02 & 0.55 & 4.2 & \multicolumn{2}{|c|}{0.45} & 0.15 & 20.11 \\
\hline & & \multicolumn{2}{|r|}{8} & & & & 9.34 & 43.43 & 76 & 0.90 & 118 & 7.45 & & 3.66 & 1145.78 \\
\hline \multicolumn{2}{|c|}{ Water bodies } & & 39.17 & 332 & & & .33 & 0 & 0 & 27.73 & 0 & 1515 & & 0 & 2381.23 \\
\hline Culti & ted land & & 25.99 & 3954.2 & & & 9.13 & 11077.93 & 902.84 & 1800.8 & 1614 & 6277. & & 8915.06 & 35087.08 \\
\hline Gras & land & & .090 & 1.41 & & & 0 & 2037 & 13.54 & 101.3 & 19.3 & 2.75 & & 31.51 & 2206.9 \\
\hline Bush & and shrubs & & 17.18 & 0 & & & 8.3 & 0 & 4.24 & 71.92 & 767.08 & 1000 & & 1635.8 & 3734.52 \\
\hline Rive & ide vegetation & & 4.70 & 775.37 & & & 2.27 & 174.1 & 264.76 & 7.1 & 383.22 & 36.7 & & 31.72 & 2109.97 \\
\hline Bare & & & 1 & 2.81 & & & 93 & 254.7 & 380.88 & 18.73 & 26.56 & 531.1 & & 3315.9 & 4532.69 \\
\hline Tota & $(1972)$ & & 749 & 5427.7 & & & 85 & 15314 & 5160 & 2029.03 & 2933.8 & 9897 & & 17610 & 60705.56 \\
\hline S.N & Class name & & 197 & & & 198 & & & 1992 & 20 & & 20 & & & 019 \\
\hline & & & Area (ha) & $\%$ area & Area & (ha) & $\%$ area & Area (ha) & 1) $\%$ area & Area (ha) & $\%$ area & Area (ha) & $\%$ area & Area (ha) & ) \% area \\
\hline 1 & Built-up area & & 497 & 0.55 & 53 & 6 & 0.60 & 541 & 0.61 & 1029 & 1.15 & 4420 & 4.94 & 8897 & 9.92 \\
\hline 2 & Natural forest & & 5543 & 6.18 & 10 & 11 & 1.13 & 647 & 0.72 & 181 & 0.20 & 147 & 0.16 & 106 & 0.13 \\
\hline 3 & Plantation fore & & 2082 & 2.32 & 11 & 18 & 1.25 & 529 & 0.59 & 398 & 0.44 & 292 & 0.33 & 497 & 0.55 \\
\hline 4 & Water body & & 15577 & 17.36 & 142 & 209 & 15.83 & 2024 & 2.26 & 1207 & 1.35 & 130 & 0.14 & 263 & 0.29 \\
\hline 5 & Cultivated land & & 26403 & 29.43 & 401 & 56 & 44.76 & 65700 & 73.23 & 70003 & 78 & 69610 & 77.59 & 64843 & 72.27 \\
\hline 6 & Grass land & & 2359 & 2.63 & 10 & 49 & 1.17 & 310 & 0.35 & 297 & 0.33 & 445 & 0.5 & 330 & 0.37 \\
\hline 7 & Bushes and Shr & ubs & 8183 & 9.12 & 161 & 49 & 18 & 12559 & 13.99 & 9404 & 10.48 & 10982 & 12.24 & 13215 & 14.73 \\
\hline 8 & River side vege & tation & 11132 & 12.42 & 93. & 59 & 10.42 & 1277 & 1.42 & 4907 & 5.47 & 1430 & 1.59 & 1235 & 1.38 \\
\hline 9 & Bare land & & 17936 & 19.99 & 61 & 34 & 6.84 & 6125 & 6.83 & 2286 & 2.58 & 2256 & 2.51 & 326 & 0.36 \\
\hline & Total & & 89712 & 100 & 897 & 12 & 100 & 89712 & 100 & 89712 & 100 & 89712 & 100 & 89712 & 100 \\
\hline
\end{tabular}


In the above table the row total sums the amount of land area for each LULC types of the year 1972 and column total sums the amount of land area that was converted to each LULC types of the year 2019. The bold diagonal values represent the area of each LULC class that remained unchanged while the off-diagonal values represent the changed area. The values in each of the cells represent the amount of land that was converted from one LULC type to another. The transition probability matrix showed that during the study period between 1972 and 2019 about 60705.56 ha of the total landscape of the study area was converted from one LULC type to the other. From all LULC types, built-up area experienced the lowest persistence with 749 ha conversion to another land use type, whereas bare lands and water bodies was the most persistent with 17610 hectares and 15314 hectares respectively.

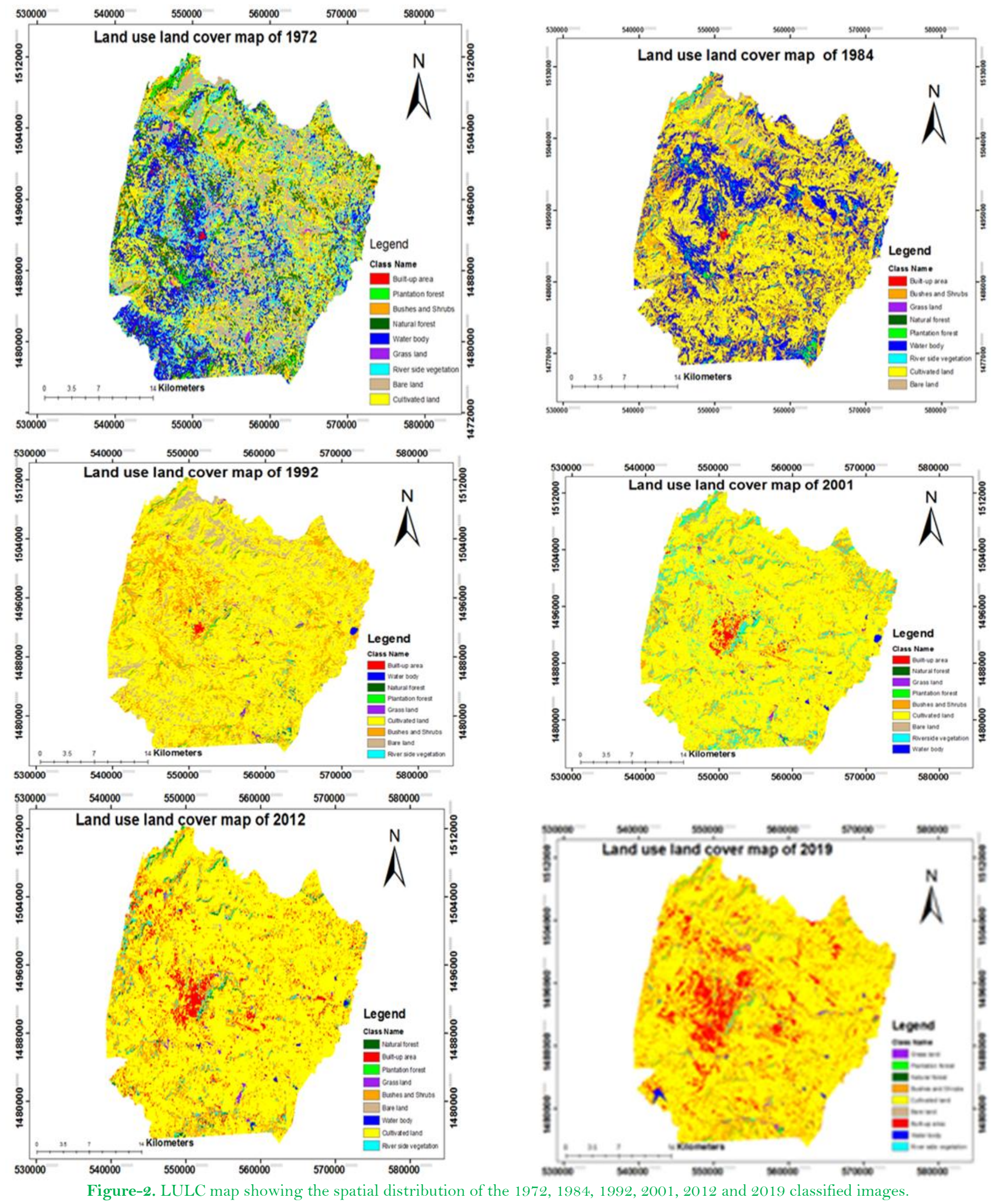




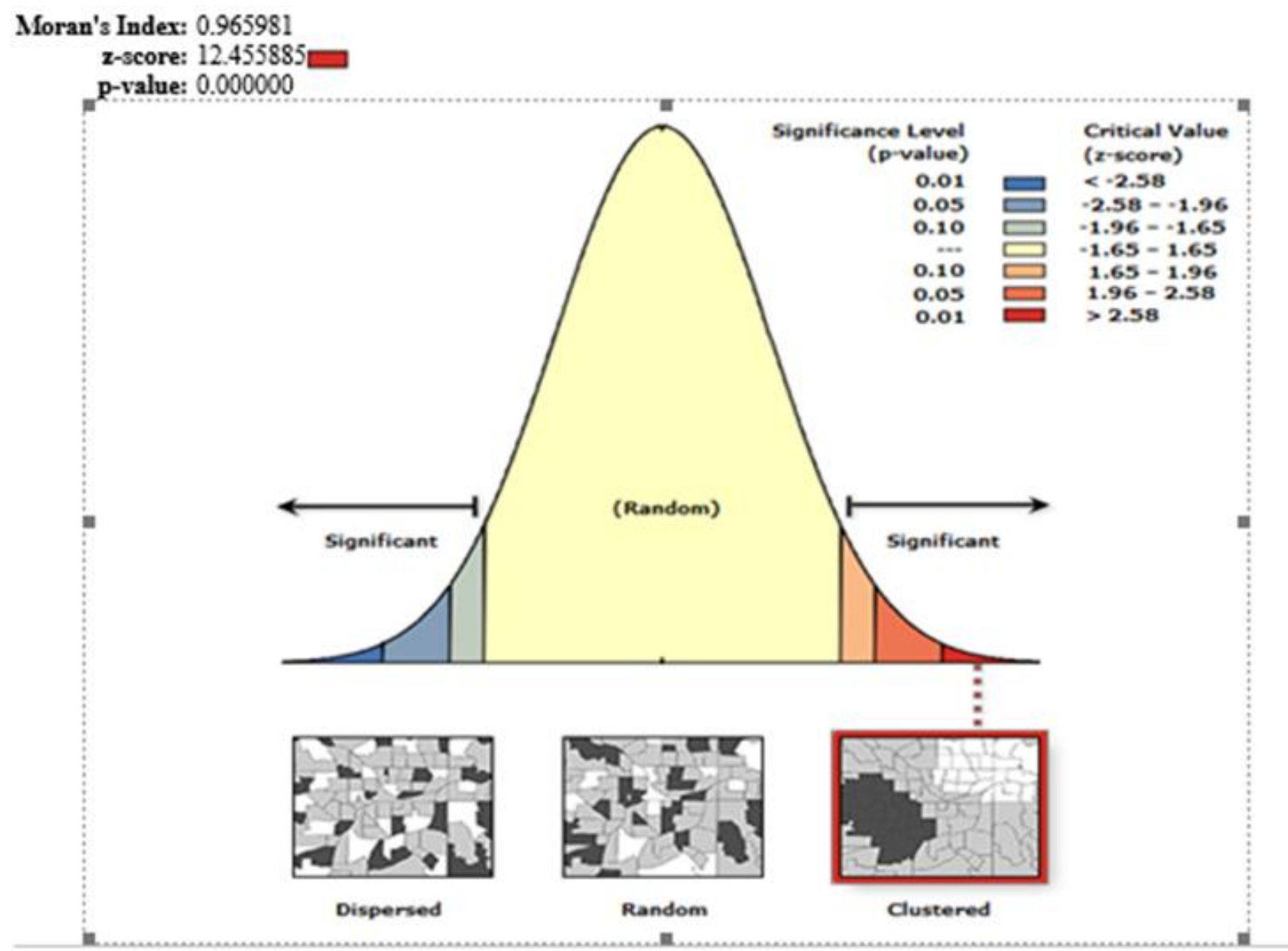

Figure-3. Spatial autocorrelation of the temporal and spatial trend of LUCC.

From the spatial autocorrelation report, the P-value result indicates there is strong evidence of rejecting the null hypothesis. The null hypothesis Ho: there was no significant change in land use pattern of the city region in the past 47 years is clearly not rejectable. Hence, the $\mathrm{H}_{1}$ : is accepted there was a significant change in the land use pattern of the city region. The high z-scores 12.455885 is associated with very small p-values. Morgan's index is 0.965981 which is positive spatial autocorrelation and shows values that are clustered.

\subsection{Drivers of LULC Dynamics in Mekelle City Region}

In the study area, both population number and population density (Figure 4 ) were increased from 93,163 in 1972 to 556127 in 2019 [12]. The population density in the Mekelle city region within 47 years increased from 104 to 620 which is greater than the initial period by $596.15 \%$ persons per square kilometer between $1972-2019$ and higher than the national average in 1972 i.e., 30.14 person per square $\mathrm{km}$. The current population density is much higher than the national population density of Ethiopia which is 109.22 people per square $\mathrm{km}$ as of 2018 .

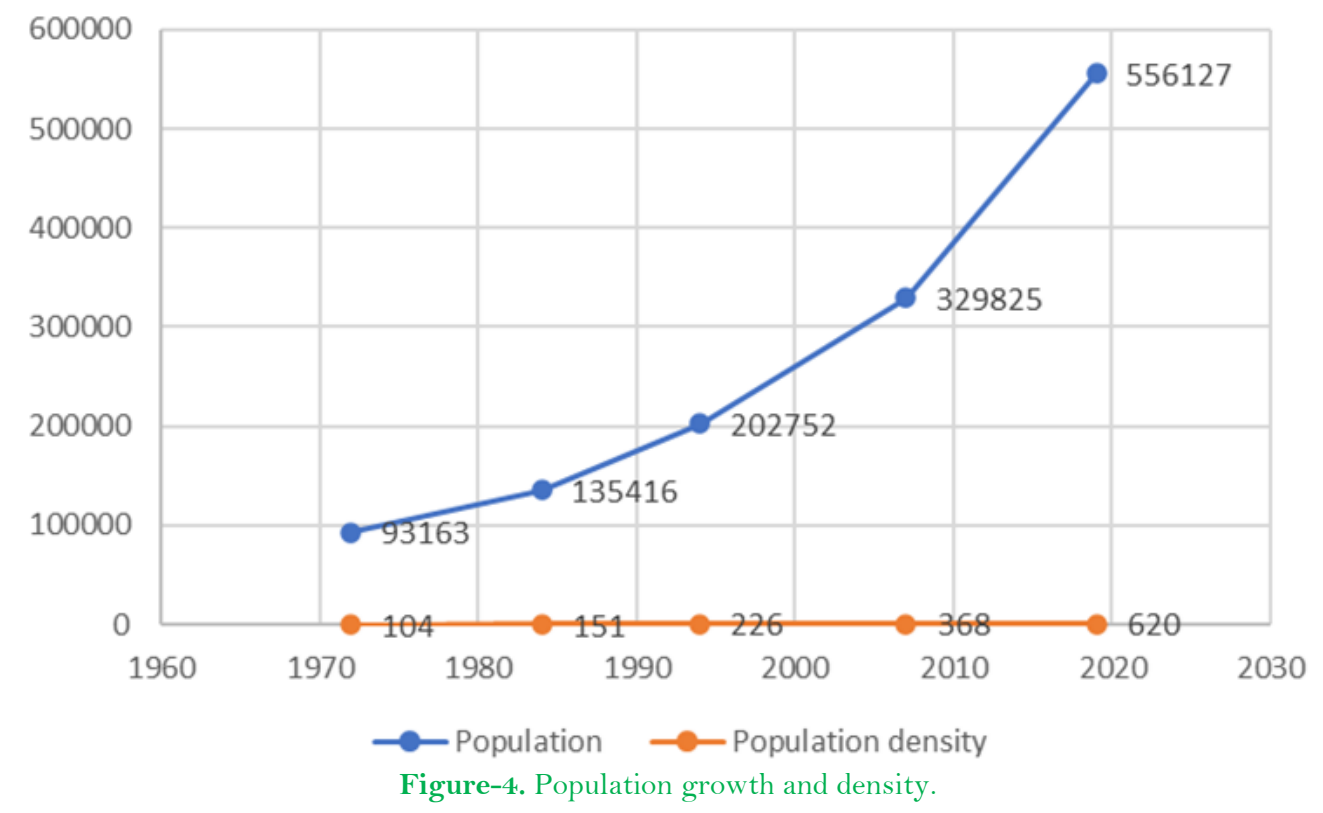

The number of populations is continuously increasing. At the same time, the resource consumption per capita shows increment. This has leads to an increasing dependency on the city regions on ecosystem service. The city still depends on its hinterland for the provision of water, several ecosystem services and the most important and largest material flux into urban ecosystems. Demographic change was the most important indirect driver for changing ecosystem services in the study area. The land use dynamics increased with population density change. 


\subsection{Climate Variability}

The study scrutinizes the historical climatic from 1972-2018(Figure 5) and the consequence these had on LULC changes in Mekelle city region. Temporal changeability of climatic conditions, such as temperature happened over the last 47 years in Mekelle city region.

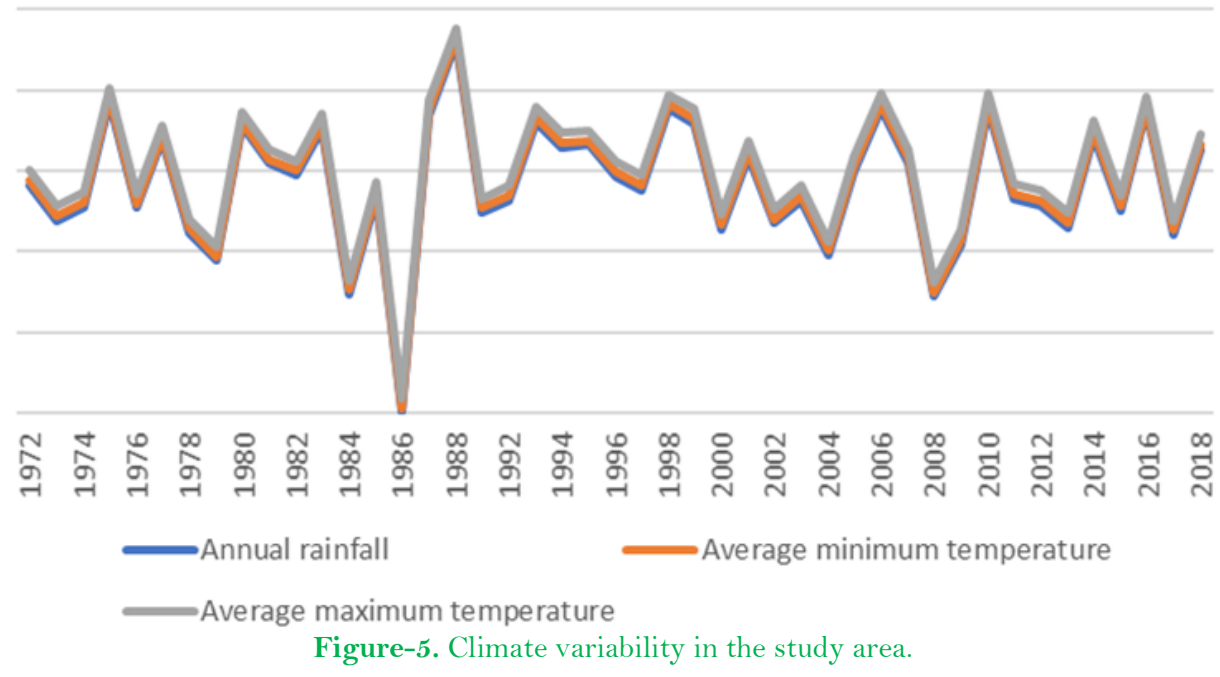

Table-6. Structural equation model regression results

\begin{tabular}{|c|c|c|c|}
\hline \multicolumn{4}{|l|}{ Fitting target model: } \\
\hline \multicolumn{4}{|l|}{ Iteration $0: \log$ likelihood $=-1328.0484$} \\
\hline \multicolumn{4}{|l|}{ Iteration 1: $\log$ likelihood $=-1328.0484$} \\
\hline Structural equation model & & \multicolumn{2}{|c|}{ Number of observations $=54$} \\
\hline \multicolumn{4}{|l|}{ Estimation method $=\mathrm{ml}$} \\
\hline \multicolumn{4}{|l|}{ Log likelihood $=-1328.0484$} \\
\hline \multicolumn{4}{|l|}{ OIM } \\
\hline Coef. Std. Err. $z$ & $\mathbf{P}>\mathbf{z}$ & [95\% Conf. & Interval] \\
\hline \multicolumn{4}{|l|}{ Structural } \\
\hline \multicolumn{4}{|l|}{ lulcc $<-$} \\
\hline tem 0.0141970 .01510890 .94 & 0.000 & 0.015416 & 0.04381 \\
\hline rai 0.00009570 .00019630 .49 & 0.000 & 0.0002891 & 0.0004805 \\
\hline pop 0.00279720 .00032358 .65 & 0.000 & 0.0021631 & 0.0034313 \\
\hline dem 0.00105780 .00009810 .79 & 0.000 & 0.0008657 & 0.0012499 \\
\hline slope 0.03460790 .001849818 .71 & 0.000 & 0.0309824 & 0.0382334 \\
\hline dis $-0.43662160 .0486337-8.98$ & 0.000 & -0.531942 & -0.3413013 \\
\hline _cons - $1.439772 .4447163-3.24$ & 0.001 & -2.3114 & -0.5681439 \\
\hline var(e.lulcc) 0.01770410 .0034072 & 0.0121412 & 0.025816 & \\
\hline LR test of model vs. saturated: $\operatorname{chi} 2(0)=$ & 0.00 & \multicolumn{2}{|c|}{ Prob $>$ chi $2=$} \\
\hline
\end{tabular}

The results show the six drivers namely temperature, rainfall, population, DEM, slope, and distance have significantly affected LULC changes in the study area in the past five decades. The biophysical factors terrain characteristics (slope and elevation) areas among the main factors causing land-use change. Based on SEM model the P-value for each non-stationary LULC driving force indicates for all the six drivers the P-value is < 0.05. Hence, there is strong evidence to reject the Ho: Driving forces of land use patterns do not bring LULC changes.

\subsubsection{Local Elderly Persons Perceptions on Driving Forces}

The key informants described that there was substantial dependency on wood for house hold consumption and this was a threat to various ecosystems like forest, bushes and shrubs, riverine vegetation that cause of environmental degradation. Furthermore, farmers clear the forest and change the land into cultivated land. According to key informants during the imperial times, the customary land tenure contributed to the expansion of settlements and agriculture. They believe the observed speedy expansion of cultivation and built-up expansion attributed to the policy and strategy changes. Agricultural encroachment on other lands and expanding built-up areas. Such changes in land use patterns have also been observed all part of the study area. Wetlands are destroyed and replaced by infrastructure, farmland, housing development.

According to the qualitative data obtained through interview, the climatic condition has changed significantly. They described a trend towards a shorter rainy season that starts later and finishes earlier with a relatively less predictable pattern. Particularly, the major events that brought LULC changes include: the severe droughts of $1984 / 85$. This increased the pressures on the ecosystem, resulting in an expansion of cultivation; increase in dry years during the last 3 decades; and rapid population growth that increases the demand for various ecosystem services. Furthermore, many churches were built using the wood from these areas.

One of the local elderly persons from an area known as Shibta stated that "Rain are no longer coming in the beginning of June but start to rain in mid-June and end in the mid of August. In the past, they were getting rainfall from mid-May/ early June till the end of September and mid-October. And the extent of the rain seasons has decreased and only get rainfall for two months or less'. As a result, declining of rivers and streamflow is threatened the ecosystem and the provision of drinking water". 


\section{Discussion}

Landsat series and semi-structured interview has been used in analyzing LULC changes. This study utilizes ERDAS imagine software synchronized with google earth which is currently worldwide used technology. The spatio-temporal analysis is not possible through other LULC analysis and mapping software. Because synchronization of google earth with ERDAS imagine increase the LULC classification accuracy of different resolutions. On the basis of interpretation of remote sensing imageries, field surveys and interview with local elderly persons and existing study area geographical conditions, the study have classified the study area into nine categories. The different types of the LULC classes have experienced significant changes during past 5 decades in the various parts of the study area.

Many methods of accuracy assessment have been reviewed in the remote sensing literature and the most widely promoted and used, is confusion or error matrix [13]. The study used error matrix for accuracy assessment. Without accuracy assessment the quality of map or output produced would be of lesser value to the end user. Supervised and unsupervised techniques show different levels of accuracy after accuracy assessment was conducted. Therefore, this study used supervised image classification based on the knowledge area of the study area to increase the accuracy of the remote sensed data. In an accuracy assessment of map data, the map was compared with higher quality data, reference data collected by ground survey through sample-based approach.

In the 1972 the results show that Mekelle city region was rich in various ecosystem types particularly the water body such as the rivers and streams were perennial that has continuous flow of water all year round during years of normal rainfall, and there was rich river side vegetation and currently the rivers and stream water is temporary and flow ceases immediately after the rainy season as per the information obtained from local elderly persons and the researcher knowledge of the study area. On the other hand, at the end of the study period 2019 reveals that cultivated land, bushes and shrubs, built-up land has tremendously expanded at the expenses of other ecosystem types. Despite it is a dominant classis of cultivated land it has showed reduction comparing with previous study decades.

The LULC analysis from remote sensing was supported by observations and perceptions from the ground. The observed changes are investigated from satellite images and from the ground through interviews. The remote sensed results provide valuable understandings the city region LULC changes, which could not have been captured through other sources of data in short period of time. From the interview it is proved that decreased in water body, natural forests, river side vegetations while cultivated land and built-up areas has increased tremendously between the years 1972 and 2019. The qualitative data generated a deeper understanding of the LULC change and discovered the shrinkages of various ecosystem types. The limitations of satellite data were supported with qualitative data. The local communities on the LULC change considerably agree with data from satellite images analysis. The remote sensing result corresponded quite well with the qualitative data findings from local elderly persons. Through comparing both quantitative and qualitative data the differences and similarities between them has been proved.

Various land use/ land cover types are transformed or interchanged into another one or more forms. The results of the study agree with other scientific local studies previously conducted on LULC changes at river basin level. The study area is part of the great Giba river basin and the results shows there is a significant LULC changes. A study by Gebremicael, et al. [14] in Tekeze-Atbara basin, Ethiopia on longitudinal land use change from land degradation shows $72 \%$ of the landscape has changed its category during the past 4 decades but recently increasing of vegetation cover resulted from intensive watershed management programs has been recorded. The Geba basin is one of the most water stressed areas of Ethiopia, with only a short rainy period from mid-June to mid-September due to consistent erratic rainfall in both time and space in the last decades [15]. In agreement to the result of this study Teferi, et al. [16] showed that swap change of the gains and losses among LULC categories is more important in recognizing the total change than the net change. According to Abraha [17] a study in Giba catchment the land use is dominated by cultivated land, followed by Bushed, grassland and bare land. Grasslands, forests, water bodies, and built-up areas only cover small fractions of the catchments.

The observed data show several ecosystems are dramatical losing and an increase in built-up area, cultivated land, bushes and shrubs due to land use dynamics. According to Millennium Ecosystem Assessment [18] in recent years, African grassland, woodland, and other vegetated areas have increasingly been converted into cropland and other land uses. In the study area, similar tendency has been found where cultivated land and built-up areas have increased tremendously.

The findings from both quantitative and qualitative data proves the worth of combining remote sensing with local perceptions have principal role in to understand land use dynamics. Qualitative data alone cannot capture the large-scale patterns of LULC changes. But quantitative data from remote sensing provides a valuable indication of LULC changes, which was explored more in-depth using qualitative data. In recent years few studies have attempted to link community levels data, observation to remotely sensed data on LULC changes. The local elderly person perception about the last 47 years increased the confidence of the spatial data results. The LULC trend changes in the study area have generated ecosystem services sustainability challenges. Here, identifying more sustainable land-use options requires solid theoretical foundations on the major causes of those changes. Understanding the LULC change from the perspective of socioecological system is vital for designing strategies to address the sustainability challenges.

The complex and diverse interactions among social-ecological systems make hard to identify and quantify the main drivers of LULC changes [19]. To fill this gap, the study used biophysical and anthropogonic drivers followed by mixed research approach to identify the key drivers for LULC changes. Analysis of LULC changes at multiple scales demands conceptual frameworks and analytical methods that are both comprehensive enough to capture the dynamics of society-environment interactions at different scales [20].

The 1972 satellite image of the study area showed there were relatively undisturbed areas that had been serving as a home of various ecosystem with varying levels of density and ground cover. This data is also corroborated by the key informants. Based on evidence obtained from the local elderly persons, cultivated land, water body, natural forest and bare land were the major LULC classes during in 1970s. During this period the ownership of land was feudal and most of the land was rich in ecosystem. The spatial analysis of the 1972 Image 
revealed that cultivated land constituted the largest proportion of land. This is because, during the 1972 the area was characterized as relatively low population. The built-up area increment was huge starting from the year of 2001 and was increased from 541 ha to 1029 ha of previous study period 1992 which was increased by $90.2 \%$; the built-up area of the year 2012 was greater than 2001 by 3391 ha $(329.5 \%)$ and the increment of year 2019 was greater than 2012 by 4477 ha $(101.3 \%)$. These results show that the built-up area rapidly grow from 2001 onwards. The expansion of both rural and urban settlement and infrastructure expansion took the largest share by converting other land cover types. This was aggravated due to continuous increase of population number they need additional land for settlement area. The expansion of cultivated land as shown on the satellite images was confirmed by the key informants that indicated that the land conversion was caused by the high numbers of the youths, who were looking for land because no employment opportunities outside agricultural sector was available at that time.

Farmers have been exchanging land among themselves through various arrangements to be able to grow food in proximity to their residence. The expansion of cultivated land as shown on the satellite images was confirmed by interviews with inhabitants that indicated that the land conversion was caused by the high numbers of the population growth. In line with this, globally population growth has been positively associated with the expansion of agricultural and urban land, land intensification, and deforestation [21]. This expansion of agriculture was supported by government plans and created opportunities to be expanded. Between the mid-1975s and mid-1980s, the LULC changes were encouraged by government policy on agriculture and land tenure, and readily bought into by farmers accelerated. These drivers contributed to a transformation in the land use patterns.

During the military government Derg after 1975 made efforts to improve the agricultural systems through the establishment of cooperatives and bare land, vegetation areas have been converted into cultivated lands. The human population of the study area was increased dramatically in the study period. On the other hand, ecosystems like forest and plantation forest, water body, riverine vegetation showed negative increment. The greater percentage increase of population number over cultivated, forest, shrub and grazing lands showed that population growth is a major driving force for these changes. In this case, the high population growth increased demand for agricultural products and result the expansion of cultivated land at the expense other ecosystem types. In line with this, a study by Tsegaye, et al. [22] describe demographic factors related to population growth as among the primary causes for LULC changes in Ethiopia.

The results from natural forest analysis show that within 12 years from 1972-1984 a loss of 4532 hectare was recorded which is severe destruction in-terms of forest ecosystem. And from 1984-1992 364 hectares was reduced which shows continuing deforestation of forests, again from 1992-2001 a reduction of 466 ha was observed. And again from 2001-2012 of 34 ha was reduced, and from 2012-2019 a reduction of 41 hectares is recorded. As reported from the key informants it is obvious that the most important factor in the destruction of forests is the human activities for housing construction and wood for charcoal.

Both natural and plantation forests amongst other ecosystems have been degraded during the last 5 decades continuously. The following drivers or factors are the main causes for such degradation: Changing of land use from forest into pasture, agriculture and urban, as a result of population growth and general land scarcity, use of the wood as a source of heat and energy in economically poor area and increase in fuel consumption. The plantation forest result show there was a reduction of 964 ha between 1972-1984, and continually it shows continuous reduction from 1984-1992 reduced by 589 ha,1992-2001 educed by 131,2001-2012 reduced by 106 ha. But from 2012-2019 it shows an increase of 205 ha $(70 \%)$. This is due to afforestation programme. The plantations were established through government and international aid programs following the increased demand in construction and fuel woods [23].

The 2007 population and housing census results show that the population of Ethiopia grew at an average annual rate of 2.6 percent between 1994 and 2007 and the annual rates of population growth for Tigray regions is also almost the same as the national rate [14]. Similarities the study area is one of the highly populated of Tigray region. The population growth demanded more land for cultivation, more trees for domestic fuelwood consumption and more area for settlement. The population growth led to increased consumption of ecosystem services that affected the supply. The population dynamics are so far, important drivers affecting both demand and supply of ecosystem services in Mekelle city region. Due to the city's rapid urbanization the surrounding forests are cut down annually mainly for the purpose of extracting charcoal, fire wood, for the construction of residential area and roads as well as expansion of farm lands in the surrounding areas [24].

The water body showed continuously declining of 1368 ha between 1974 and 1984, a dramatic decrease of 12185 between 1984-1992, from 1992-2001 a decrease of 817, from 2001-2012 a reduction of 1077 ha and from 2012-2019 a positive increase of 133 ha was observed due to construction different types of water structure of dams and ponds. Despite, the recent increment of water body due to construction of water structure like dams and ponds this study found that the water body was affected several times by recurrent drought of climate changes. Particularly during the 1985 there was heavy drought in northern Ethiopia in Tigray and Wollo. The LULC change results show that the periods between 1984-1992 there was severe damage and reduction of ecosystem in water body, natural and plantation forest, bushes and shrubs, river side vegetation and grass lands. There was severe drought that costs the lives of mankind. Due to the serious drought in 1985, the farmland was intensively used for cultivation, as the quality of the land had shown deterioration in quality and as some of the residents were come from other parts of Tigray and settled in the study area.

To substantiate the ecosystem reduction, the climate variability trend analysis obtained from historical metrological data was validated by local elderly persons perceptions. The majority of the respondents ranked climate related factors as the first order driver. Their perception about rainfall is in agreement with the meteorological data analysis. The droughts have negatively impacted the ecosystem causing further degradation, as people sought alternative means of survival such as cutting of trees to prepare charcoal. Further, the variation in inter-annual rainfall amount causes differences in vegetation. In semi-arid highlands of northern Ethiopia, incidents of droughts of varying severity and duration occur. The occurrence of these droughts is associated mainly with the seasonal rainfall variability for the period 1954-2008 and the study shows that the northern part of Ethiopia is warming faster than the national average of $0.25^{\circ} \mathrm{C}$ per decade [25]. 
Tigray experiences major environmental hazards of rainfall instabilities causing droughts and famine, earthquakes, invasions of locust swarms, and epidemics [26]. The cultivated land in Mekelle city region expanded due to an increase the vulnerability of human environment system to climate fluctuation causes land degradation. In Ethiopia, the driving forces, have adverse effects of loss of biodiversity and ecosystem service degradation [27].The rainfall in Ethiopia is highly variable and unpredictable in time and space [28].

The study finds climate variability have affected various ecosystem particularly the water bodies in the last 47 years in the study area. The LULC changes and climatic change in combination with soil deterioration alter the hydrological cycle, thereby progressively degrading the ecosystem and reducing the quality of water ecosystem. Changes in LULC of at catchment level modify the availability of water resources of a basin in complex ways [29]. This study shows land use dynamics at catchment scale can also affect not only water but also other types of the ecosystem services.

The results from bushes and shrubs prove that between 1972-1984 an increase of 7966 ha was observed. Despite this, in the period of 1984-1992 and 1992-2001 there was a reduction of 3590 ha and 3155 ha respectively. In between 2001-2012 and 2012-2019 there was an increase of 1578 ha and 2233 ha respectively. This is due to policy on environmental rehabilitation through integrated watershed management, and the associated implementation programs, has been the key driver behind the observed increasing trend. The numerical result from bare land indicates that a continuous reduction from of 1972-1984, 1984-1992, 1992-2001,2001-2012 and 2012-2019 it reduced by 11802 ha,9 ha,3839,30 and 1930 hectares respectively. This indicate bare lands are encroached by urbanization and currently there are 326 hectares of bare lands. Though the ecosystem restoration is not fast the period 1992-2001 was a turning point for ecological restoration for river side vegetations and bare land significantly reduced. And the year 2001-2012 was a turning point for grass land, bushes and shrubs. However, it is very important to realize from 2012-2019 there is a hope for ecological restoration.

The findings show that the need of social-ecological systems as complex adaptive systems for policy development. Understanding the city region as socio-ecological system can have the opportunity to manage its resilience towards sustainability. The urban areas and neighbouring rural areas together have to sustain the energy, material and ecosystem services flows. Focusing on the local scale of the city has its pitfalls, as it fails to take account of those cross-scaling feedbacks. This is because Mekelle city is not self-sufficient in terms of the ecosystem services provision on which it depends on a scale that extends well beyond the urban administrative boundaries where local interventions take place. Recognising the social and environmental challenges that cities need to deal with, long-term urban decision-making under climate change and resource scarcity is crucial to help understand the complexity of the interdependencies in ecological, social and economic systems across scales and time which could help forecast and avoid unintended effects. These resources range from basics such as water and food, to economic goods and information. Cut off these supplies to the modern city of Mekelle can negatively affect the total function of the city. Hence, this study concluded complex adaptive system theory have a great contribution to understand the relationships between the Mekelle city and its environs to achieve sustainable urbanization.

\section{Conclusion and Recommendations}

This study analyzed land use dynamics and its driving forces using various sources of data. Using a mixed methods approach helped to gain a wide perspective on the identified research problem. The change detection analysis showed that substantial land cover change that had occurred. Significantly, the LULC features are dynamically transformed to another land uses due to anthropogonic requirement of the local people and climate variability. From this study it is inferred that there were significant changes in vegetations and water bodies. Unfortunately, most of the LULC features are transformed to build-ups and settlements and other land uses without considering their negative impacts on ecosystems with increasing rate of vulnerability to environmental degradation. The significant changes in LULC have contributed to dwindling of numerous ecosystems. Based on the analyses there is a very high confidence that population growth and climate variability in both urban and rural is a major driver of LULC change. The ecosystem services are experiencing continuous loss. This study also found that both factors are drivers for land use dynamics in Mekelle city region. But they differ in their rank.

To sustain the ecosystem which are vital for the benefit of the people and economic development of the study area, appropriate spatial planning policy should be issued. Thus, understanding how LULC changes drivers affect ecosystem service is important to communicate with decision makers, ecologist and land planners to craft appropriate land management legal frameworks. This study can be useful for efficient watershed management since Mekelle city depend on distant watershed ecosystem services. Monitoring the negative consequences of LULC while sustaining the supply of essential ecosystem services is vital. Therefore, there is a need to design and implement appropriate spatial planning policies in city region by decision makers.

A determined and a renowned approach is required to sustain the continuum provision of ecosystem services. In this regards the following measures are suggested to ensure sustainable provision of ecosystem services and ensure sustainable landscape management in Mekelle city region, the application of spatial planning strategies is vital. In this regard, it is suggested that:((1) Continuous monitoring on land use dynamics and strengthening ecological restoration (2) Adopting watershed-based approach to improve the quality and quantity of ecosystem services (3) Launching regional green infrastructure plans and regional ecological networks (4) river side restoration (5) Further deep investigations on assessing the major drivers of LULC changes (6) Strengthening measures for the Implementation of regional spatial planning (7) Introducing regional metropolitan plan and (8) Sectoral integration of watershed management in Mekelle city region.

\section{References}

[1] J. Wu, "Landscape sustainability science: Ecosystem services and human well-being in changing landscapes," Landscape Ecology, vol. 28, pp. 999-1023, 2013.Available at: https://doi.org/10.1007/s10980-013-9894-9.

[2] A. Hermann, S. Schleifer, and T. Wrbka, "The concept of ecosystem services regarding landscape research: A review," Living Reviews in Landscape Research, vol. 5, pp. 1-37, 2011 .Available at: https://doi.org/10.12942/lrlr-2011-1. 
M. L. Martínez, O. Pérez-Maqueo, G. Vázquez, G. Castillo-Campos, J. García-Franco, K. Mehltreter, and R. Landgrave, "Effects of land use change on biodiversity and ecosystem services in tropical montane cloud forests of Mexico," Forest Ecology and Management, vol. 258, pp. 1856-1863, 2009.Available at: https://doi.org/10.1016/j.foreco.2009.02.023.

[4] M. S. I. Sohel, S. A. Mukul, and B. Burkhard, "Landscape' s capacities to supply ecosystem services in Bangladesh: A mapping assessment for Lawachara National Park," Ecosystem Services, vol. 12, pp. 128-135, 2015.Available at: https://doi.org/10.1016/j.ecoser.2014.11.015.

[5] M. Bürgi, A. M. Hersperger, and N. Schneeberger, "Driving forces of landscape change-current and new directions," Landscape Ecology, vol. 19, pp. 857-868, 2005.Available at: https://doi.org/10.1007/s 10980-005-0245-3.

[6] K. G. Turner, S. Anderson, M. Gonzales-Chang, R. Costanza, S. Courville, T. Dalgaard, and L. Porfirio, "A review of methods, data, and models to assess changes in the value of ecosystem services from land degradation and restoration," Ecological Modelling, vol. 319, pp. 190-207, 2016.Available at: https://doi.org/10.1016/j.ecolmodel.2015.07.017.

[7] J. Kleemann, G. Baysal, H. N. Bulley, and C. Fürst, "Assessing driving forces of land use and land cover change by a mixed-method approach in North-Eastern Ghana, West Africa," Journal of Environmental Management, vol. 196, pp. 411-442, 2017.Available at: https://doi.org/10.1016/j.jenvman.2017.01.053.

[8] V. H. Dale, S. Brown, R. Haeuber, N. Hobbs, N. Huntly, R. Naiman, and T. Valone, "Ecological principles and guidelines for managing the use of land sup> 1," Ecological Applications, vol. 10, pp. 639-670, 2000.Available at: https://doi.org/10.2307/2641032.

[9] T. G. A. A. V. D. Veen, "The effect of enclosures in rehabilitating degraded vegetation: A case of Enderta District, Northern Ethiopia forest research," Forest Research, vol. 3, pp. 1-7, 2014.

[10] A. G. Abreha, "Hydrogeochemical and water quality investigation on irrigation and drinking water supplies in the Mekelle region, Northern Ethiopia," Master's Thesis, University of Twente, 2014.

[11] TCSA, "Tigray population data demography," ed Ethiopia: Tigray Stastical Agency, 2019, pp. 1-70.

[12] CSA, The 1984 population census of Ethiopia. Results for Addis Ababa. Addis Ababa: Central Statistical Authority, 1985.

[13] G. M. Foody, "Status of land cover classification accuracy assessment," Remote Sensing of Environment, vol. 80, pp. 185-201, 2002.Available at: https://doi.org/10.1016/s0034-4257(01)00295-4.

[14] Y. A. M. Gebremicael, P. van der Zaag, and E. Y. Hagos, "Quantifying longitudinal land use change from land degradation to rehabilitation in the headwaters of Tekeze-Atbara Basin," ed Ethiopia: Elsevier, 2017, pp. 1581-1589.

[15] T. Gebreyohannes, F. De Smedt, K. Walraevens, S. Gebresilassie, A. Hussien, M. Hagos, and K. Gebrehiwot, "Application of a spatially distributed water balance model for assessing surface water and groundwater resources in the Geba basin, Tigray, Ethiopia," Journal of Hydrology, vol. 499, pp. 110-123, 2013.Available at: https://doi.org/10.1016/j.jhydrol.2013.06.026.

[16] E. Teferi, W. Bewket, S. Uhlenbrook, and J. Wenninger, "Understanding recent land use and land cover dynamics in the source region of the Upper Blue Nile, Ethiopia: Spatially explicit statistical modeling of systematic transitions," Agriculture, Ecosystems $\mathbb{E}^{2}$ Environment, vol. 165, pp. 98-117, 2013.Available at: https://doi.org/10.1016/j.agee.2012.11.007.

[17] A. Z. Abraha, "Assessment of spatial and temporal variability of river discharge, sediment yield and sediment-fixed nutrient export in Geba River catchment, Northern Ethiopia," Katholieke Universiteit Leuven, Faculty of Sciences, Belgium2009.

[18] M. Millennium Ecosystem Assessment, Ecosystems and human well-being. Island Press Washington, DC, 2005.

[19] E. Ostrom, "A general framework for analyzing sustainability of social-ecological systems," Science, vol. 325, pp. 419-422, 2009.Available at: https://doi.org/10.1126/science.1172133.

[20] D. J. Campbell, D. P. Lusch, T. A. Smucker, and E. E. Wangui, "Multiple methods in the study of driving forces of land use and land cover change: A case study of SE Kajiado District, Kenya," Human Ecology, vol. 33, pp. 763-794, 2005.Available at: https://doi.org/10.1007/s10745-005-8210-y.

[21] Q. Weng, Remote sensing and GIS integration: Theories, methods, and applications. New York: McGraw-Hill, 2010.

[22] D. Tsegaye, S. R. Moe, P. Vedeld, and E. Aynekulu, "Land-use/cover dynamics in Northern Afar Rangelands, Ethiopia," Agriculture, Ecosystems \&ं Environment, vol. 139, pp. 174-180, 2010.Available at: https://doi.org/10.1016/j.agee.2010.07.017.

[23] T. Abate and A. Angassa, "Conversion of savanna rangelands to bush dominated landscape in Borana, Southern Ethiopia," Ecological Processes, vol. 5, pp. 1-18, 2016.Available at: https://doi.org/10.1186/s13717-016-0049-1.

[24] K. Moges, "People's awareness and perception level on the risks of climate change and constraints of their adaptation strategies in Mekelle City, Tigray Regional State, Ethiopia," Civil and Environmental Research, vol. 8, pp. 1-17, 2016.

[25] T. Gebrehiwot and A. van der Veen, "Assessing the evidence of climate variability in the Northern part of Ethiopia," Journal of Development and Agricultural Economics, vol. 5, pp. 104-1 19, 2013.Available at: https://doi.org/10.5897/jdae12.056.

[26] K. A. Bard, M. Coltorti, M. C. DiBlasi, F. Dramis, and R. Fattovich, "The environmental history of Tigray (Northern Ethiopia) in the Middle and Late Holocene: A preliminary outline," African Archaeological Review, vol. 17, pp. 65-86, 2000.

[27] M. Muke, "Reported driving factors of land-use/cover changes and its mounting consequences in Ethiopia: A Review," African Journal of Environmental Science and Technology, vol. 13, pp. 273-280, 2019.Available at: https://doi.org/10.5897/ajest2019.2680.

[28] K. Tesfagiorgis, T. Gebreyohannes, F. De Smedt, J. Moeyersons, M. Hagos, J. Nyssen, and J. Deckers, "Evaluation of groundwater resources in the Geba basin, Ethiopia," Bulletin of Engineering Geology and the Environment, vol. 70, pp. 461-466, 2011.Available at: https://doi.org/10.1007/s10064-010-0338-3.

[29] Y. B. Liu, F. De Smedt, L. Hoffmann, and L. Pfister, "Assessing land use impacts on flood processes in complex terrain by using GIS and modeling approach," Environmental Modeling \& Assessment, vol. 9, pp. 227-235, 2005.Available at: https://doi.org/10.1007/s 10666-005-0306-7. 